University of Warwick institutional repository: http://go.warwick.ac.uk/wrap This paper is made available online in accordance with publisher policies. Please scroll down to view the document itself. Please refer to the repository record for this item and our policy information available from the repository home page for further information.

To see the final version of this paper please visit the publisher's website. Access to the published version may require a subscription.

Author(s): Richard C. AMEY, Anna ATHEY-POLLARD, Claire BURNS, Peter R. MILLS, Andy BAILEY and Gary D. FOSTER

Article Title: PEG-mediated and Agrobacterium-mediated transformation in the mycopathogen Verticillium fungicola

Year of publication: 2002

Link to published version:

http://dx.doi.org/10.1017/S0953756201005251

Publisher statement: None 


\title{
PEG-mediated and Agrobacterium-mediated transformation in the mycopathogen Verticillium fungicola
}

\author{
Richard C. AMEY ${ }^{1}$, Anna ATHEY-POLLARD ${ }^{1}$, Claire BURNS ${ }^{1}$, Peter R. MILLS ${ }^{2}$, Andy BAILEY ${ }^{1}$ \\ and Gary D. FOSTER ${ }^{1 *}$ \\ ${ }^{1}$ School of Biological Sciences, University of Bristol, Woodland Road, Bristol BS8 1UG, UK. \\ ${ }^{2}$ Horticulture Research International, Wellesbourne, Warwick CV35 9EF, UK. \\ E-mail: Gary.Foster@bristol.ac.uk \\ Received 27 May 2001; accepted 10 September 2001.
}

Verticillium fungicola, a severe mycopathogen of the cultivated mushroom Agaricus bisporus, was successfully transformed using both PEG-mediated and Agrobacterium-mediated techniques. PEG-mediated co-transformation was successful with hygromycin B resistance $(h p h)$, uidA ( $\beta$-glucuronidase GUS), and green fluorescent protein (GFP) genes. Agrobacterium-mediated transformation was successful with the $h p h$ gene. Transformation frequencies of up to 102 transformants per $\mu \mathrm{g}$ DNA and 4068 transformants per $10^{5}$ conidia were obtained for PEG-mediated and Agrobacterium-mediated transformation respectively. Expression of integrated genes in co-transformants was stable after 18 months of successive sub-culturing on non-selective medium, and following storage at $-80{ }^{\circ} \mathrm{C}$ in glycerol. Molecular analysis of PEG-mediated transformants showed integration of the transforming genes into the target genome. Molecular analysis of Agrobacterium-mediated transformants showed integration of transforming DNA as single copies within the target genome. Co-transformants exhibited symptoms of disease in inoculation experiments and were at least as virulent as the wild-type fungus. GFP and GUS expression were observed in-vivo with the GFP-tagged strain showing great potential as a tool in epidemiological and host-pathogen interaction studies. The development of transformation systems for $V$. fungicola will allow in-depth molecular studies of the interaction of this organism with A. bisporus.

\section{INTRODUCTION}

The mycoparasite Verticillium fungicola var. fungicola is the causal agent of the disease dry bubble in the cultivated white button mushroom Agaricus bisporus. Of all the pathogens infecting mushrooms, fungal diseases are responsible for the greatest losses to the mushroom industry, with $V$. fungicola posing the greatest threat. The process by which $V$. fungicola infects the mushroom is not well understood (Calonje et al. 1997, 2000) as the fungus:fungus interaction is complex. Specialised penetration structures observed by Dragt et al. (1996) and direct penetration play a role in the infection process as does the action of extracellular enzymes produced by the pathogen.

To date control of $V$. fungicola involves two distinct approaches: (1) traditional control consisting of strict hygiene, cultural practices and manipulation of environmental conditions (Jeffries \& Young 1994), the

* Corresponding author. ultimate aim of which is preventing disease outbreaks; and (2) application of approved fungicides when disease risk is high (Fletcher, White \& Gaze 1986). Disease control in late flushes is difficult to achieve using hygiene alone, and the only available compound for control, Prochloraz manganese (Aventis), does not give $100 \%$ control and is being phased out due to environmental concerns over resistance build-up and high residue levels in mushroom farm waste (Dragt et al. 1996).

The mushroom industry is in need of novel and effective control methods for $V$. fungicola. The development of an efficient transformation system may advance studies of the pathogen and may ultimately lead to a broader range of control strategies. A transformation system could be used to elucidate genes and associated pathways responsible for $V$. fungicola pathogenicity, by analysing gene function and expression. Indeed, a number of studies have shown that complementation and disruption of putative pathogenicity genes gives a good indication of their in- 
volvement in infection within plant systems (Talbot et al. 1993, Bowyer et al. 1993, Rohe et al. 1995). This may also be applied to the infection of mushrooms. Transformation of $V$. fungicola may allow further studies involving targeted gene disruptions, reporter gene fusions and insertional mutagenesis by restriction enzyme mediated integration (REMI) and T-DNA tagging.

To date studying and monitoring of individual $V$. fungicola isolates in mushroom houses has been difficult due to an inability to visualize the pathogen in-vivo. This may be improved by transforming $V$. fungicola with selectable markers and reporter genes such as $\beta$ glucuronidase (GUS) and green fluorescent protein (GFP). This may allow the epidemiology of $V$. fungicola, and the molecular basis of its interaction with $A$. bisporus to be examined further.

Until recently, PEG-mediated transformation of protoplasts has been the method of choice for filamentous fungi. However, an established method for plant transformation by Agrobacterium tumefaciens has been further developed for use in yeast (Bundock et al. 1995), and a number of filamentous fungi (de Groot et al. 1998, Gouka et al. 1999, Covert et al. 2001, Mullins et al. 2001). It was decided to investigate both these methods for the transformation of $V$. fungicola.

Here PEG-mediated co-transformation of $V$. fungicola protoplasts using vectors conferring resistance to hygromycin B, GUS activity and GFP activity, is described. Transformation of $V$. fungicola to hygromycin B resistance using Agrobacterium-mediated transformation is also demonstrated. Integration of transforming DNA is studied by Southern hybridization, with the stability and properties of vector DNA integration being investigated and discussed. Virulence tests demonstrate the efficacy of the transformant strains as tools for pathogen detection and epidemiology in vivo.

\section{METHODS}

\section{Fungal strains}

All experiments were with Verticillium fungicola isolate CBS 440.34 (Centraalbureau voor Schimmelcultures, Utrecht), a standard infective strain of Agaricus bisporus originally isolated from a diseased mushroom, which was stored as mycelium at $-80{ }^{\circ} \mathrm{C}$ in $30 \%$ glycerol. For experimental purposes cultures were grown in potato dextrose broth (PDB, Oxoid), malt extract agar (MEA: malt extract broth, Oxoid $+2 \%$ agar), or on potato dextrose agar (PDA: $\mathrm{PDB}+2 \%$ agar) at $24^{\circ}$.

\section{Protoplast preparation}

A $500 \mu \mathrm{l}$ spore suspension $\left(1 \times 10^{6}\right.$ spores $\left.\mathrm{ml}^{-1}\right)$ was inoculated into PDB and incubated at $20^{\circ}$ with constant shaking (150 rev $\left.\mathrm{min}^{-1}\right)$ for $2 \mathrm{~d}$. Fungal cells were harvested by centrifugation $(3600 \mathrm{~g}, 30 \mathrm{~min})$ and washed twice in $10 \mathrm{ml} 0.6 \mathrm{M} \mathrm{KCI}$. Fungal cells were re- suspended in either $10 \mathrm{ml} 20 \mathrm{mg} \mathrm{ml}^{-1}$ Novozyme 234 (Interspex Products, USA) in SCS (1 M sorbitol; $20 \mathrm{~mm}$ sodium citrate), or $10 \mathrm{ml} \beta$-D-glucanase (Interspex Products, USA) and driselase (Interspex Products, USA) both at $10 \mathrm{mg} \mathrm{m}^{-1}$ in SCS and shaken

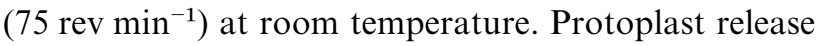
was monitored by light microscopy. When $90 \%$ protoplasting was achieved the protoplasts were filtered through sterile Miracloth (Calbiochem, USA) and centrifuged $(2000 \mathrm{~g}, 10 \mathrm{~min})$, washed twice in $10 \mathrm{ml}$ SCS, and washed once more in $10 \mathrm{ml} \mathrm{STC2}(1 \mathrm{M}$ sorbitol; $10 \mathrm{~mm}$ Tris-HCl; $100 \mathrm{~mm} \mathrm{CaCl}_{2}, \mathrm{pH}$ 7.5). The protoplasts were then adjusted to a concentration of $2 \times 10^{4}$ protoplasts $\mathrm{ml}^{-1}$ in STC2 and stored on ice until required.

\section{Transformation}

The transformation vector pAN7-1 (Punt et al. 1987) contains the hygromycin B phosphotransferase resistance gene $(h p h)$ from Escherichia coli regulated by an Aspergillus nidulans promoter $(g p d \mathrm{~A})$ and terminator $(\operatorname{trp} \mathrm{C})$. Vector pST28 (from Paul Bowyer, IACR, Long Ashton) contains the $h p h$ gene regulated by the $A$. nidulans trp $\mathrm{C}$ promoter and terminator. The vector pNOM102 contains a $\beta$-glucuronidase gene (uidA) from $E$. coli regulated by an $A$. nidulans promoter $(g p d \mathrm{~A})$ and terminator $(\operatorname{tr} p \mathrm{C})$. The vector $\mathrm{pGPDGFP}$ contains a GFP gene regulated by an $A$. nidulans promoter $(\operatorname{gpd} \mathrm{A})$ and terminator $(\operatorname{trp} \mathrm{C})$. For fungal transformation plasmid DNA was prepared using the Qiagen midi-prep kit.

Transformation of protoplasts was carried out essentially as described by Hargreaves and Turner (1992), with selection using $5 \mathrm{ml}$ Czapek-Dox agar amended with $1 \mathrm{M}$ sorbitol and a final overall hygromycin B concentration of $200 \mu \mathrm{g} \mathrm{ml}^{-1}$.

Agrobacterium-mediated transformation was carried out with plasmid vector pBIN7.1, built essentially as described by de Groot et al. (1998). The plasmid pBIN7.1 was constructed by digesting pAN7.1 with $B g l \mathrm{II}$ and HindIII. This resulted in a $3201 \mathrm{bp}$ fragment containing a $g p d \mathrm{~A}$ promoter, $h p h$ gene and trpC terminator. The fragment was inserted into pBIN19 (Bevan 1984) between the left and right border sequences as described by de Groot et al. (1998).

$100 \mu \mathrm{l}$ of $3.2 \times 10^{4}$ and $3.2 \times 10^{5}$ conidia $\mathrm{ml}^{-1}$ were mixed with $100 \mu \mathrm{l}\left(8.4 \times 10^{6}\right.$ cells $)$ A. tumefaciens strain LBA1126 containing pBIN7.1, and plated out on cellophane disks on induction media (IM) (Hooykaas, Roobol \& Schilperoort 1979). Control plates not amended with acetosyringone were included for each conidial concentration plated. After $2 \mathrm{~d}$ incubation, the cellophane disks with germinating conidia were transferred to cefotaxime $\left(200 \mathrm{\mu g} \mathrm{ml}^{-1}\right)$ and hygromycin B $\left(550 \mu \mathrm{g} \mathrm{ml}^{-1}\right)$ selection medium to kill the Agrobacterium and select for transformants respectively. After growing for $4 \mathrm{~d}$, colonies were sub-cultured on minimal medium (Hooykaas, Roobol \& Schilperoort 1979) 
amended with hygromycin B $\left(550 \mu \mathrm{g} \mathrm{ml}^{-1}\right)$ to maintain selection. After a further $4 \mathrm{~d}$, remaining colonies were sub-cultured on to hygromycin B and cefotaxime selection plates as before, and on to control plates without hygromycin B, to ensure that viable Verticillium fungicola colonies had been transferred. Colonies that grew strongly on hygromycin B plates were selected for further analysis.

\section{Analysis of transformants}

\section{Expression of GUS}

GUS expression was determined fluorometrically as follows: $2 \mathrm{ml}$ molten PDA containing $2 \mu \mathrm{M}$ methylumbelliferyl $\beta$-D-glucuronide (MUG, Melford) was pipetted into each well (16 $\mathrm{mm}$ diam) of a flat-bottomed 24-well micro-titre plate. 23 wells were inoculated with a $5 \mathrm{~mm}$ plug of putative hygromycin B-resistant/GUSexpressing Verticillium fungicola co-transformants. The remaining well was inoculated with wild-type CBS 440$34 \mathrm{~V}$. fungicola. After incubation at room temperature for $3 \mathrm{~d}$ GUS activity was assessed using a long wavelength UV emitter. One good GUS-expressing colony (designated 440GUS) was selected for further analysis.

Histochemical visualization of GUS activity in isolates potentially transformed with the GUS gene, and in Agaricus bisporus infected with a GUS transformant, was carried out as follows: Potentially transformed mycelium or $1 \mathrm{~mm}$ sections of infected $A$. bisporus were placed on microscope slides. These were treated with $500 \mu \mathrm{ll} 10 \mathrm{~mm}$ sodium phosphate buffer (pH 7.5) supplemented with $20 \mu \mathrm{l}$ 5-bromo-4-chloro-3indolyl glucuronide (X-gluc) and incubated overnight at room temperature in the dark. The slides were then examined macro- and microscopically.

\section{Expression of GFP}

Putative GFP-expressing colonies were identified using a LEICA DMLB fluorescence microscope fitted with an I3 blue filter set. One good GFP-expressing colony (designated 440GFP) was selected for further analysis.

\section{Confirmation of transformation by PCR}

Isolation of genomic DNA for analysis of transformants was essentially carried out as described by Keon \& Hargreaves (1998). PCR was carried out with genomic DNA for PEG-mediated co-transformants and Agrobacterium-mediated transformants. Primers designed to amplify part of the $h p h$ gene were used for amplification (Hygl-5'-GCGTGGATATGTCCTGCGGG-3' and Hyg2-5'-CCATACAAGCCAACCACGG-3'). The following protocol was used in PCR $\left(94^{\circ} 2 \mathrm{~min} ; 30\right.$ cycles of $\left.94^{\circ} 30 \mathrm{~s}, 50^{\circ} 30 \mathrm{~s}, 72^{\circ} 30 \mathrm{~s} ; 72^{\circ} 4 \mathrm{~min}\right)$. The same primers and protocol were used with pAN7.1 as a template to obtain a probe for use in Southern analysis.

\section{Confirmation of transformation by Southern analysis}

Southern analysis was carried out on each transformant (440GUS, 440GFP, and five Agrobacterium-mediated transformants) and wild-type genomic DNA. $10 \mu \mathrm{g}$ samples of genomic DNA were digested with appropriate restriction enzymes. Restriction fragments were separated by electrophoresis, blotted on to Hybond-N membrane (Amersham Pharmacia Biotech) and fixed by UV cross-linking. Probes were radiolabelled with ${ }^{32} \mathrm{P}$-dCTP using the rediprime ${ }^{\mathrm{TM}} \mathrm{II}$ random prime labelling system (Amersham Pharmacia Biotech). Following hybridization X-ray film was exposed to the filter for $5 \mathrm{~h}$.

\section{Virulence testing of co-transformants}

Mushroom compost spawned with Agaricus bisporus mycelium (Amycel 2100) was used to assess the efficacy of 440GFP and 440GUS strains as tools in $V$. fungicola epidemiology. The spawn-run compost was placed in 10 -inch pots and cased. The pots were incubated in the dark at $17^{\circ}$ with $85 \%$ relative humidity $(\mathrm{RH})$ and were inoculated with 5000 spores in $100 \mathrm{ml}$ sterile distilled water of their respective $V$. fungicola strains, $12 \mathrm{~d}$ after casing (before pinning was visible). The treatments were A: 440GFP, B : 440GUS, C: CBS 440-34 wild type and $\mathrm{D}$ : Sterile distilled water. The pots were arranged in a randomized block design in the growth chamber and were assessed periodically for expression of disease symptoms and yield at each flush. Four replicates of each treatment were used.

\section{RESULTS}

\section{Analysis of PEG-mediated transformants}

To enable effective transformation to be investigated the intrinsic resistance of Verticillium fungicola to hygromycin B was established. V. fungicola mycelium and conidia of the strain used grew on CDA at concentrations up to but not including $50 \mu \mathrm{g} \mathrm{ml}^{-1}$ hygromycin B. With PDA and malt extract agar (MEA: malt extract broth, Oxoid $+2 \%$ agar) the minimum inhibitory concentration was higher than that for CDA, with $200 \mu \mathrm{g} \mathrm{ml}^{-1}$ and $>200 \mu \mathrm{g} \mathrm{ml}^{-1}$ hygromycin B needed to suppress growth respectively (data not shown). Protoplasting was equally efficient with Novozyme 234 and a blend of driselase and glucanase, giving between 15000 and 20000 protoplasts $\mathrm{ml}^{-1}$.

The $V$. fungicola isolate was co-transformed with the plasmids pAN7-1 or pST28 in conjunction with either pNOM102 or pGPDGFP via PEG-mediated transformation of protoplasts. The same isolate was also transformed using the plasmid pBIN7.1 via Agrobacterium-mediated transformation.

The stability of transformants was assessed by three successive sub-cultures on hygromycin $\mathrm{B}$ amended CDA $\left(500 \mu \mathrm{g} \mathrm{ml}^{-1}\right)$. Transformants were then cultured 


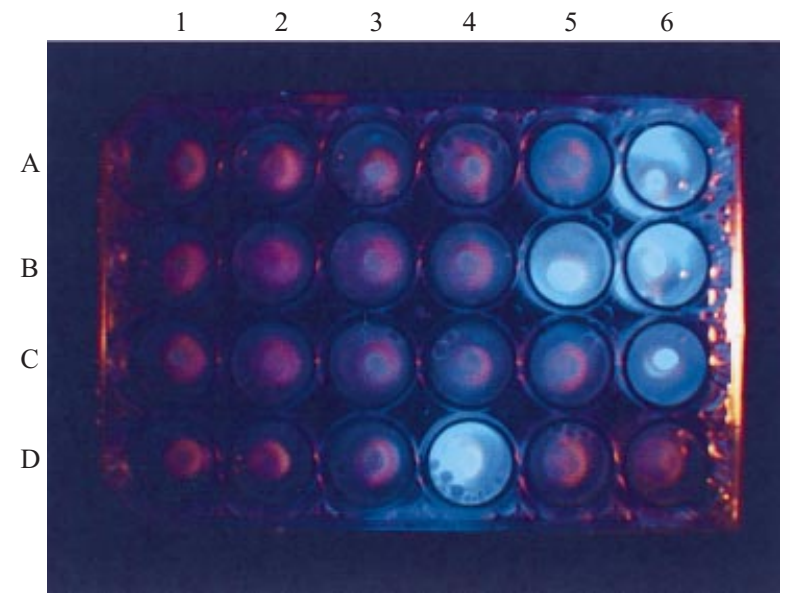

Fig. 1. $\beta$-glucuronidase activity detected by a MUG assay. MUG plate assay assessing transformants for the presence of $\beta$-glucuronidase (GUS) activity. Wells A6, B5-6, C6 and D4 are all positive for GUS activity as indicated by fluorescence. Well D1 is wild-type Verticillium fungicola CBS 440-34. D4 is transformed with pAN7-1 and pNOM102. All other positives (A6, B5, B6 \& C6) are transformed with pST28 and pNOM102.

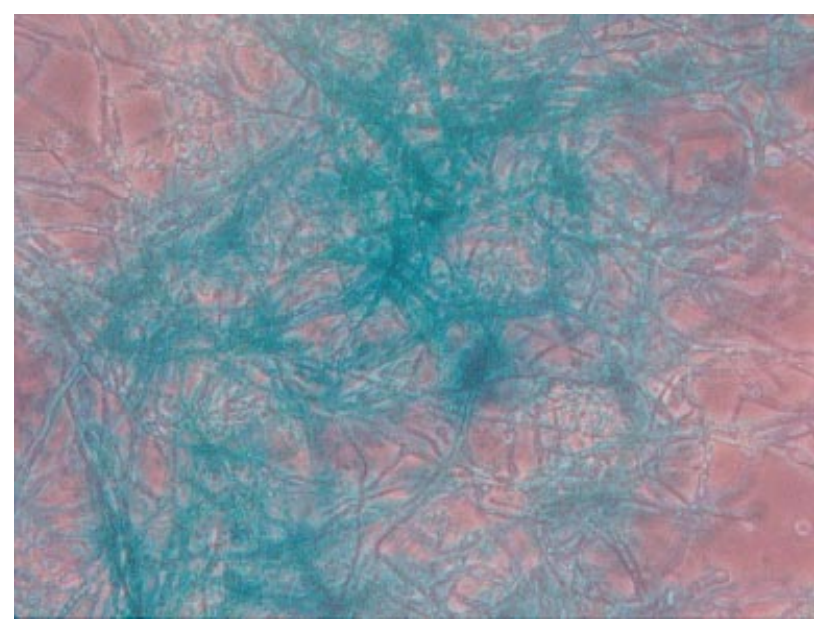

Fig. 2. $\beta$-glucuronidase activity can be detected using $X$-gluc as a substrate. Photomicrograph of histochemical visualization of GUS activity within GUS-tagged Verticillium fungicola (440GUS) grown in liquid culture $(\times 10)$.

on CDA without antibiotic selection followed by CDA amended with $500 \mathrm{\mu g} \mathrm{ml}^{-1}$ hygromycin B. Transformants were stored at $-80^{\circ}$ in glycerol stocks and remained stable upon subsequent sub-culture. Single spore colonies of the selected transformants were used for further analysis.

Transformation rates were extremely variable with zero to 102 transformants per $\mu \mathrm{g}$ DNA. Co-transformation efficiency varied depending upon the plasmid used.

From 57 pAN7-1/pNOM102 and 102 pST28/ pNOM102 transformants, 23 were selected at random and assessed for $\beta$-glucuronidase expression using the MUG microtitre plate assay (Fig. 1). Five of the transformants assessed showed activity. One of these

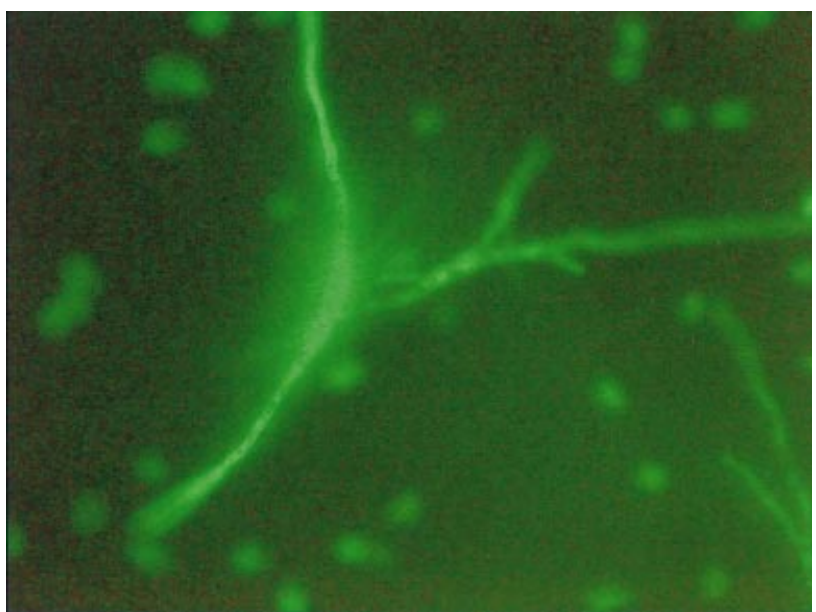

Fig. 3. Verticillium fungicola co-transformed with pGPDGFP and pAN7-1 expresses strong fluorescence. Photomicrograph of GFP-tagged mycelium grown in liquid culture and observed microscopically with UV light $(\times 100)$. $\begin{array}{lll}1 & 2 & 3\end{array}$

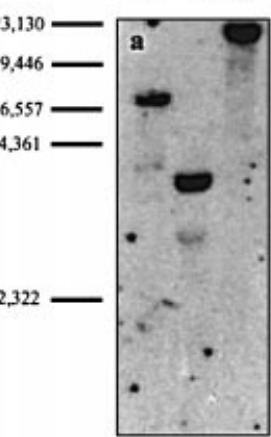

$\begin{array}{lll}4 & 5 & 6\end{array}$

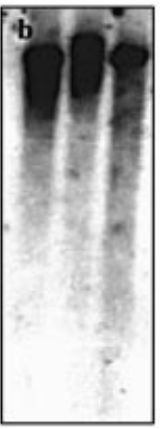

$\begin{array}{lll}7 & 8 & 9\end{array}$

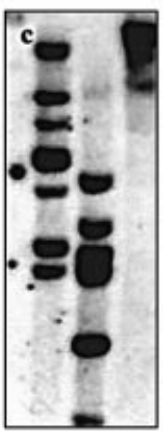

101112

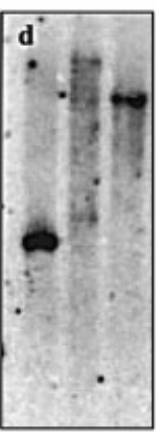

Fig. 4. PEG-mediated transformation, with transforming DNA integrating randomly and in varying copy number into the target DNA. (a)-(b) Genomic DNA of 440GUS (a) and 440GFP (b) was digested with EcoRI (lanes 1 and 4), KpnI (lanes 2 and 5) and SalI (lanes 3 and 6) and was probed with a $600 \mathrm{bp} h \mathrm{~h} h$ fragment obtained by PCR using pAN7-1 as a template. Single bands of varying size in lanes 1 and 3 indicate single copy random integration of the pAN7-1 DNA into the genome of the GUS co-transformant. Lane 2 did not resolve successfully. Multiple bands of varying sizes in lanes 4-6 indicate multi-copy, multi-locus random integration of the pAN7-1 DNA into the genome of the GFP co-transformant. (c) 440GUS genomic DNA digested with EcoRI, KpnI and BamHI in lanes 7-9 respectively, was probed with a $2000 \mathrm{bp}$ NcoI pNOM102 fragment. Single bands of varying sizes in lanes 7-9 indicate single copy random integration of the pNOM102 transforming DNA into the target genome. (d) 440GFP genomic DNA digested with EcoRI, PstI and $K p n \mathrm{I}$ in lanes $10-12$ respectively was probed with a $1 \mathrm{~kb} E c o$ RI pUCGFP fragment. Single bands in lanes 10-12 of varying sizes indicate single copy random integration of the pGPDGFP transforming DNA into the target genome. Selected molecular weight size markers are indicated.

was transformed using the plasmid pAN7-1, the other four with the plasmid pST28 as the selectable marker for hygromycin B resistance. This shows that cotransformation of $V$. fungicola by PEG-mediated 


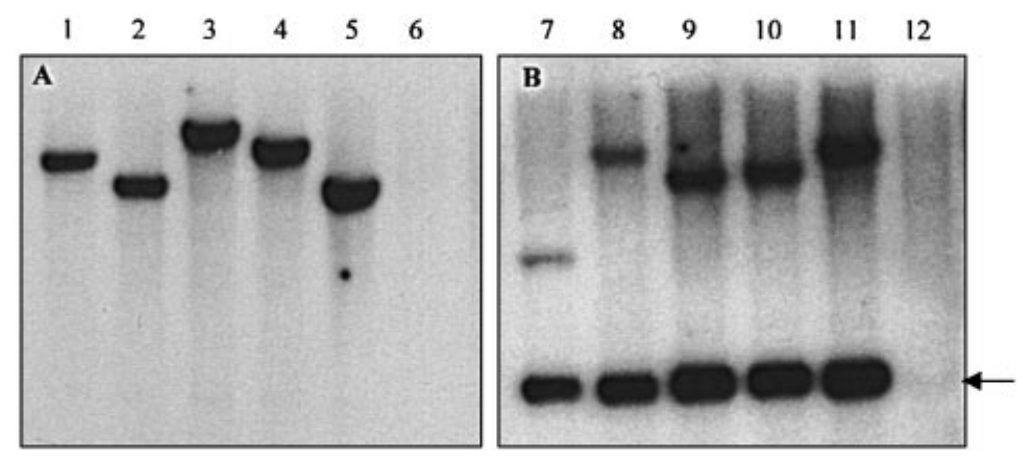

Fig. 5. Transforming DNA integrating randomly and in single copy number into the target DNA. A 550 bp $P v u I I-N c o$ I fragment from pBIN7.1. was used to probe the Agrobacterium-mediated transformants. (a) Lanes 1-5. HindIII digests of genomic DNA from five Agrobacterium-mediated transformants selected at random; Lane 6. Wild-type Verticillium fungicola 440-34 genomic DNA. HindIII cuts once in the transforming DNA and once in the genomic DNA. The differing band sizes indicate integration at random loci, and the single bands show single integration events. (b) Lanes 7-11. EcoRI digests of genomic DNA from five Agrobacterium-mediated transformants selected at random; Lane 12 . Wild-type $V$. fungicola 440-34 genomic DNA. EcoRI cuts twice in the transforming DNA (once in the 550 bp region used as a probe), and once in the genomic DNA. Cutting the two sites within the vector generates the $2.4 \mathrm{~kb}$ band indicated. This band would be expected to have a greater intensity as it has $441 \mathrm{bp}$ homologous to the probe, compared to $109 \mathrm{bp}$ for the bands of variable size. The presence of different sized bands shows random integration, and two bands confirm single integration.

methods is successful. One transformant, designated 440GUS (pAN7-1 \& pNOM102) was selected for further molecular analysis and was checked for histochemical localization of GUS activity (Fig. 2).

Twelve putative GFP transformants were obtained using plasmids pAN7-1 and pGPDGFP. These were assessed visually for GFP (Fig. 3) as described above. Three transformants expressed GFP, with one (440GFP) being selected for further molecular analysis. This particular isolate was chosen for comparison of pAN7-1 integration in the GFP co-transformant with the GUS co-transformant under separate transformation events. Fluorescence was not observed in the wild-type strain.

After initial PCR analysis to check for the presence of transforming DNA, Southern hybridisation showed that the probes for the hygromycin $\mathrm{B}$ resistance, $\beta$ glucuronidase and GFP genes did not hybridise to digested wild-type 440-34 genomic DNA. The probe for the hygromycin $\mathrm{B}$ gene hybridised to one or more fragments in digested DNA of the PEG-mediated transformed strains, thus confirming integration of the plasmid into the genomes of the transformants (Figs 4a-b). 440GUS (Fig. 4a) shows single bands when examined with a probe for the hygromycin $\mathrm{B}$ resistance gene, indicating single copy integration. 440GFP (Fig. 4b) shows multiple bands when screened with a probe for the hygromycin B resistance gene, indicative of multi-copy, multi-locus integration. Although difficult to determine accurately, it is estimated that three to four copies of the hygromycin B resistance gene are present in 440GFP. The GUS probe and the GFP probe hybridised to one fragment in the GUS (Fig. 4c) and GFP (Fig. 4d) transformants respectively, confirming single copy integration of the respective plasmids into the genomes of these transformants. The different hybridisation patterns for the hygromycin Bresistant transformants indicates that integration can occur singly, and in multiple copies for protoplast transformation.

\section{Analysis of Agrobacterium-mediated transformants}

Hygromycin B-resistant transformants were generated using $A$. tumefaciens strain LBA1126 transformed with the vector $\mathrm{pBIN7}-1$. This was mixed with $V$. fungicola strain 440-34 conidia and transformation was induced by incubation on induction medium. 4068 putative transformants were obtained from $8.6 \times 10^{5}$ conidia. Putative hygromycin B-resistant transformants were sub-cultured on to minimal medium amended with $550 \mathrm{\mu g} \mathrm{ml}^{-1}$ hygromycin B. Five transformants were selected at random for further analysis. Growth of transformants was exhibited at hygromycin B concentrations up to $2 \mathrm{mg} \mathrm{ml}^{-1}$.

After initial PCR analysis to check for the presence of transforming DNA, Southern analysis confirmed that the probe for the hygromycin B-resistance gene hybridised to all Agrobacterium-mediated transformants, indicating integration of the plasmid pBIN7-1 into the genomes of all strains tested (Figs 5a-b). The HindIII digest indicates single integration events at random loci, with the EcoRI digest confirming this. EcoRI cuts twice in the transforming DNA and once in the genomic DNA. The $2.4 \mathrm{~kb}$ band generated has $441 \mathrm{bp}$ homologous with the probe, compared to $109 \mathrm{bp}$ for the variable sized bands. This results in the greater intensity of the $2.4 \mathrm{~kb}$ band. The second bands of varying sizes indicate random integration. The two bands again indicate that single integration events have occurred. Interestingly only one copy of the T-DNA was observed in all transformants tested, all of which 

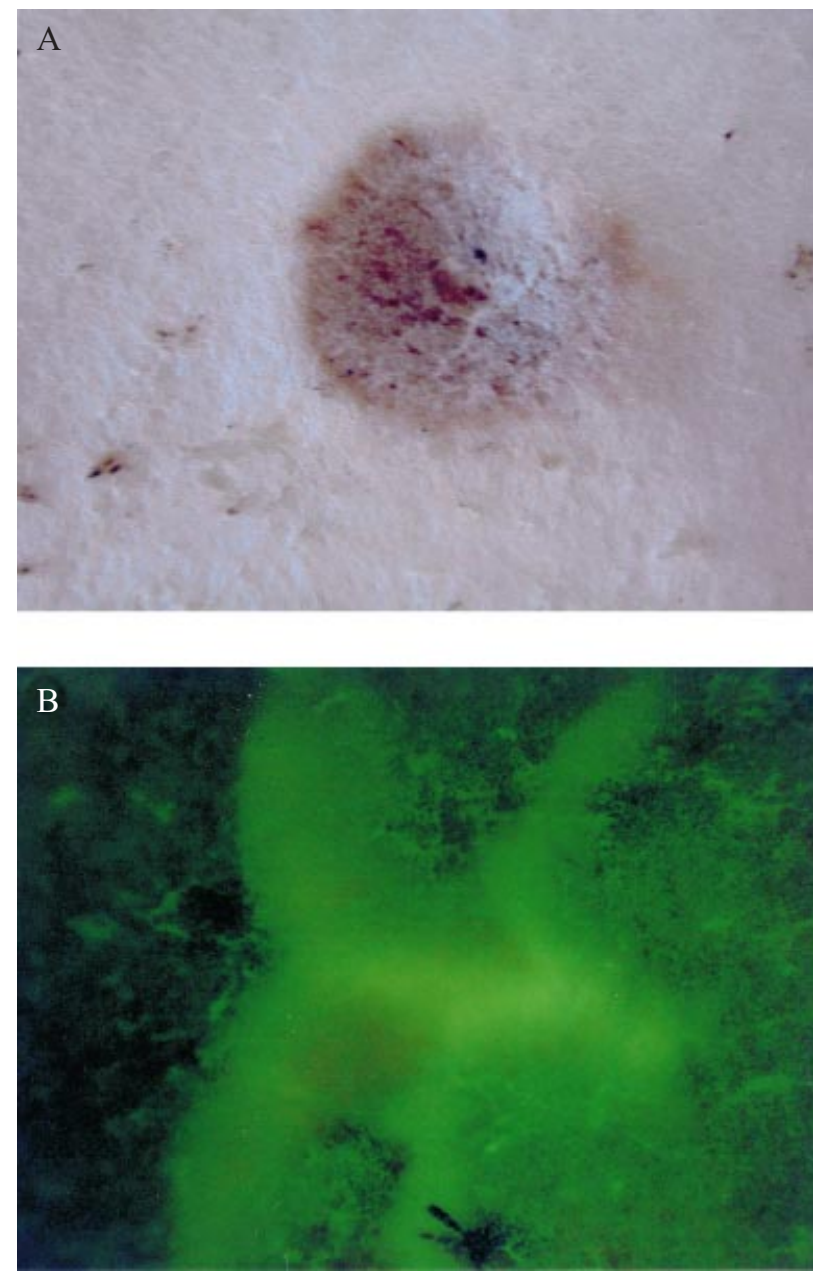

Fig. 6. Isolate $440 \mathrm{GFP}$ as a tool to track Verticillium fungicola infection in vivo in Agaricus bisporus. (a) Infection of $A$. bisporus by the V. fungicola GFP-tagged transformant (440GFP) resulting in a necrotic lesion on the mushroom cap. (b) Microscopic examination of the spotting symptom shown in Figure 6.a and visualised using UV light. The $V$. fungicola green fluorescent hyphae can be seen clearly against the host (mushroom) tissue $(\times 10)$.

must have resulted in functional copies of the gene to enable the fungus to grow on selection medium.

\section{Assessment of virulence of co-transformants}

As hypothesised by Jones et al. (1999), it is important to know whether the constitutive Aspergillus nidulans promoters place an undesirable metabolic burden on the transformant, and to determine whether the transformants have altered in their ability to cause disease in the Agaricus host as a result of integration of transforming DNA within the genome. Initial comparison of growth rates of the co-transformants showed similarity with that of the wild-type. We then compared the co-transformants with the wild-type fungus in virulence tests on A. bisporus. Disease impact of the two strains was evaluated by measuring crop yield and assessment of symptom expression. It was observed that 440GUS and 440GFP were as virulent as the wild- type, showing similar reductions in yield (results not presented) and the three main symptoms of $V$. fungicola infection (cap spotting, stipe blow-out and dry bubble).

\section{GUS and GFP expression of co-transformants in Agaricus bisporus}

To observe GUS activity, infected mushrooms were observed following the X-gluc staining as described above. Although the GUS transformant gave blue colouration, histochemical localization of GUS activity within Verticillium fungicola mycelium in vivo within the infected mushroom proved impossible due to the high background of GUS activity generated by the host (mushroom) tissue. This may indicate that the value of the GUS transformant to investigate direct interactions with Agaricus bisporus is limited.

GFP expression of $V$. fungicola in infected mushrooms was observed as described earlier. Hyphae of the co-transformant 440GFP were barely distinguishable from the host under incident light. In contrast, 440GFP exhibited distinct green fluorescence when observed with ultra-violet light, allowing it to be clearly distinguished from its host (Fig. 6).

\section{DISCUSSION}

Transformation by PEG-mediated and Agrobacteriummediated methods succeeded in generating hygromycin B-resistant transformants. Comparison of transformation efficiency between the two techniques shows Agrobacterium-mediated transformation to be more efficient in terms of time and effort than PEG-mediated transformation, with the actual number of Agrobacterium-mediated transformants being similar to that demonstrated with other fungi (de Groot et al. 1998, Gouka et al. 1999, Covert et al. 2001, Mullins et al. 2001). It is possible to consistently obtain up to 4068 transformants per $10^{5}$ conidia with Agrobacteriummediated transformations compared to PEG-mediated protoplast transformation where transforming efficiency is unpredictable. This demonstrates the advantage of using Agrobacterium as a tool in fungal transformation. Overall the rate of PEG-mediated cotransformation is relatively low compared to fungi such as Coniothyrium minitans (Jones et al. 1999) but is similar to ratios reported with Trichoderma harzianum (Bae \& Knudsen 2000) and with biolistic co-transformation of Metarhizium anisopliae (Inglis et al. 2000).

The observations to date showing that Agrobacterium-mediated transformation only results in single copy integration events is comparable with work by Covert et al. (2001) where mostly single copy transformants were obtained with the fungus Fusarium circinatum, but differs from other fungi where both single and multiple integrations occur (de Groot et al. 1998, Gouka et al. 1999, Mullins et al. 2001). This suggests that this method is ideal for targeted mutagenesis in Verticillium 
fungicola. Random T-DNA tagging would certainly be one possibility for further investigation. Transformants could be examined for altered pathogenicity, and the cause of the changed phenotype ascertained by searching for the integration site of the T-DNA in the target genome. Protoplast-mediated transformation displays reduced value in this situation due to the unpredictable number of gene copies entering the target genome, possibly causing more than one phenotypic change.

The uidA gene has proved to be useful in the study of fungal biomass of Cladosporium fulvum and Leptosphaeria (Oliver et al. 1993), root colonisation by Fusarium oxysporum (Eparvier \& Alabouvette 1994), infection of Bipolaris sorokiniana (Lijeroth, Jansson \& Schafer 1993) and biocontrol of Sclerotinia sclerotiorum by Coniothyrium minitans (Jones et al. 1999). However, the GUS transformant has limited application as a tool for studying infection of Agaricus bisporus. This was due to the background $\beta$-glucuronidase production of A. bisporus making it difficult to distinguish between the host and pathogen. However, it may remain useful for studies of $V$. fungicola biomass and epidemiology studies in compost and casing experiments. In contrast, the GFP strain may prove to be an invaluable tool in studying the interaction of $V$. fungicola with $A$. bisporus and may also advance the study of the epidemiology of the disease and the spread through both host and compost. The possession of hygromycin-B resistant, GFP-expressing and GUS-expressing isolates will allow selective isolation, quantification and in vivo tracking of the transformants from, and in mushrooms and compost, especially as no reduction in virulence was observed. This will allow experiments to be carried out into the survival, growth, epidemiology and host colonisation of $V$. fungicola.

The establishment of these transformation systems for $V$. fungicola and validation of GUS and GFP reporter genes allows further information to be obtained on the fungus:fungus interaction between $V$. fungicola and its host $A$. bisporus by promoter:reporter fusions, REMI and T-DNA tagging of mutants. Targeted disruption of genes with potential roles in pathogenicity will be investigated.

\section{ACKNOWLEDGEMENTS}

The authors would like to thank Steve Lincoln (Horticulture Research International, Wellesbourne) for technical support and supplying isolate CBS 440.34, and Neil Willoughby (Horticulture Research International, Wellesbourne) for help and advice with mushroom cultivation. This work was partly funded by the UK Ministry of Agriculture Fisheries and Food (MAFF) and The Royal Society.

\section{REFERENCES}

Bae, Y. S. \& Knudsen, G. R. (2000) Cotransformation of Trichoderma harzianum with $\beta$-glucuronidase and green fluorescent protein genes provides a useful tool for monitoring fungal growth and activity in natural soils. Applied and Environmental Microbiology 66: 810-815.
Bevan, M. (1984) Binary Agrobacterium vectors for plant transformation. Nucleic Acids Research 22: 8711-8721.

Bowyer, P., Clarke, B. R., Lunness, P., Daniels, M. J. \& Osbourn, A. E. (1993) Host range of a plant pathogenic fungus is determined by a saponin detoxifying enzyme. Science 287 : 371-374.

Bundock, P., den Dulk-Ras, A., Beijersbergen, A. \& Hooykas, P. J. J. (1995) Trans-kingdom T-DNA transfer from Agrobacterium tumefaciens to Saccharomyces cerevisiae. EMBO Journal 14: 3206-3214.

Calonje, M., Garcia Mendoza, C., Galan, B. \& Novaes-Ledieu, M. (1997) Enzymic activity of the mycoparasite Verticillium fungicola on Agaricus bisporus fruit body cell walls. Microbiology 143: 2999-3006.

Calonje, M., Garcia Mendoza, C., Perez Cabo, A., Bernardo, D. \& Novaes-Ledieu, M. (2000) Interaction between the mycoparasite Verticillium fungicola and the vegetative mycelial phase of Agaricus bisporus. Mycological Research 104: 988-992.

Covert, S. F., Kapoor, P., Lee, M., Briley, A. \& Nairn, C. J. (2001) Agrobacterium tumefaciens-mediated transformation of Fusarium circinatum. Mycological Research 105: 259-264.

de Groot, M. J. A., Bundock, P., Hooykaas, P. J. J. \& Beijersbergen, A. G. M. (1998) Agrobacterium tumefaciens-mediated transformation of filamentous fungi. Nature Biotechnology 16: 839-842.

Dragt, J. W., Geels, F. P., de Bruijn, W. C. \& van Griensven, L. J. L. D. (1996) Intracellular infections of the cultivated mushroom Agaricus bisporus by the mycoparasite Verticillium fungicola var. fungicola. Mycological Research 100: 1082-1086.

Eparvier, A. \& Alabouvette, C. (1994) Use of ELISA and GUStransformed strains to study competition between pathogenic and non-pathogenic Fusarium oxysporum for root colonisation. Biocontrol Science \& Technology 4: 35-47.

Fletcher, J. T., White, P. F. \& Gaze, R. H. (1986) Mushrooms: pest and disease control. Intercept, Newcastle Upon Tyne.

Gouka, R. J., Gerk, C., Hooykaas, P. J. J., Bundock, P., Musters, W., Verrips, C. T. \& de Groot, M. J. A. (1999) Transformation of Aspergillus awamori by Agrobacterium tumefaciens-mediated homologous recombination. Nature Biotechnology 17: 598-601.

Hargreaves, J. \& Turner, G. (1992) Gene transformation in plant pathogenic fungi. In Molecular Plant Pathology (S. J. Gurr, M. J. McPherson \& D. J. Bowles, eds): 79-97. Oxford University Press, Oxford.

Hooykaas, P. J. J., Roobol, C. \& Schilperoort, R. A. (1979) Regulation of the transfer of Ti-plasmids of Agrobacterium tumefaciens. Journal of General Microbiology 110: 99-109.

Inglis, P. W., Aragão, F. J. L., Frazão, H., Magalhães, B. P. \& Valadares-Inglis, M. C. (2000) Biolistic co-transformation of Metarhizium anisopliae var. acridum strain CG423 with green fluorescent protein and resistance to glufosinate ammonium. FEMS Microbiology Letters 191: 249-254.

Jeffries, P. \& Young, T. W. K. (1994) Interfungal Parasitic Relationships. CAB International, Wallingford.

Jones, E., Carpenter, M., Fong, D., Goldstein, A., Thrush, A., Crowhurst, R. \& Stewart, A. (1999) Co-transformation of the sclerotial mycoparasite Coniothyrium minitans with the hygromycin B resistance and $\beta$-glucuronidase markers. Mycological Research 103: 929-937.

Keon, J. \& Hargreaves, J. (1998) Isolation and heterologous expression of a gene encoding 4-hydroxyphenylpyruvate dioxygenase from the wheat leaf-spot pathogen, Mycosphaerella graminicola. FEMS Microbiology Letters 161 : 337-343.

Lijeroth, E., Jansson, H. B. \& Schafer, W. (1993) Transformation of Bipolaris sorokiniana with the GUS gene and use for studying fungal colonisation of barley roots. Phytopathology 83: 1484-1489.

Mullins, E. D., Chen, X., Romaine, P., Raina, R., Geiser, D. M. \& Kang, S. (2001) Agrobacterium-mediated transformation of Fusarium oxysporum: an efficient tool for insertional mutagenesis and gene transfer. Phytopathology 91: 173-180.

Oliver, R. P., Farman, M. L., Jones, J. D. G. \& Hammond-Kosack, K. E. (1993) Use of fungal transformants expressing $\beta$-glucuronidase activity to detect infection and measure hyphal biomass in 
infected plant tissues. Molecular Plant-Microbe Interactions 6: 521-525.

Punt, P. J., Oliver, R. P., Dingemanse, M. A., Pouwels, P. H. \& van den Hondell, C. A. M. J. J. (1987) Transformation of Aspergillus based on the hygromycin resistance marker from Escherichia coli. Gene 56: 117-124.

Rohe, M., Gierlich, A., Hermann, H., Hahn, M., Schmidt, B. Rosahl, S. \& Knogge, W. (1995) The race-specific elicitor, NIP1, from the barley pathogen, Rhynchosporium secalis, determines avirulence on host plants of the RRS1 resistance genotype. EMBO Journal 14: 4168-4177.

Talbot, N. J., Ebbole, D. J. \& Hamer, J. E. (1993) Identification and characterisation of $M P G 1$, a gene involved in pathogenicity from the rice blast fungus Magnaporthe grisea. Plant Cell 5: 1575-1590.

Corresponding Editor: S. J. Assinder 